\title{
Achieving compliance with pool fencing legislation in New Zealand: a survey of regulatory authorities
}

\author{
Luke Morrison, David J Chalmers, John D Langley, Jonathan C Alsop, Catriona McBean
}

\begin{abstract}
Objectives-To identify the status of compliance and enforcement of New Zealand's Fencing of Swimming Pools Act (FOSP Act), 10 years after its introduction, and to identify methods for improving both compliance with the act and the process of enforcement.
\end{abstract}

Methods-A postal questionnaire was sent to all 74 authorities in New Zealand in which they were asked questions about their enforcement of the FOSP Act. Semistructured telephone interviews were conducted with 12 authorities to supplement the data obtained in the postal survey.

Results-Based on responses to the survey, it was estimated that there are over 59000 domestic swimming pools in New Zealand, giving rates of 46 pools $/ 1000$ dwellings and 16 pools/1000 persons. The authorities reported that $44 \%$ of pools complied with the act, and a further $4 \%$ had been granted exemptions. Nineteen per cent of pools were reported to not comply with the act, and the compliance status of a further $33 \%$ was not known, or not stated by the authority. Only $9 \%$ of authorities had procedures for locating and inspecting pools, while $28 \%$ had a programme of reinspection to ensure that pools continued to comply. Pool owner resistance was considered to be the main difficulty with enforcing the act, and nearly half of the authorities believed publicity or education was needed to overcome these barriers. Fifty two per cent of authorities had publicised the act during the 12 months preceding the survey.

Conclusions-Due to ambiguities within the legislation, and differing levels of commitment by authorities to locate pools and monitor compliance, compliance with the FOSP Act is not consistent nationally. If the act were less ambiguous, there would be greater consistency and more enforcement.

(Injury Prevention 1999;5:114-118)

Keywords: drowning; legislation; evaluation; pool fencing

Water Safety New

Zealand, Wellington,

New Zealand

C McBean

Correspondence to: Dr Chalmers.
For New Zealand children under 5 years of age, only motor vehicle crashes cause more injury deaths than drowning. ${ }^{1}$ Of the 289 deaths due to drowning in this age group between 1980 and 1996, 42\% occurred in domestic swimming or spa pools (Water Safety New Zealand, unpublished data). Research in other countries has also identified the domestic swimming pool as the most common place of drowning or near-drowning for preschool children, ${ }^{2-5}$ although in more temperate climates this is not the case. ${ }^{67}$

Many measures exist that have the potential to reduce drownings in domestic swimming pools, and mandatory pool fencing is considered to be the most effective of these. ${ }^{8}$ Case-control studies have shown that pool fencing reduces the risk of drowning, while other studies have shown that where pool fencing is required by law, fewer drownings occur. ${ }^{2}{ }^{\text {8-12}}$ Other measures, such as pool covers and alarms have limitations that make them less effective than fencing. ${ }^{2}{ }^{13}$ Adult supervision is also insufficient, as continuous supervision is difficult to achieve, or may not be considered essential by some parents/caregivers. Drownings or near-drownings occur in many cases when supervision has lapsed for only a few minutes, ${ }^{213-16}$ and there is no evidence to suggest supervision is better when a pool is unfenced. ${ }^{17}$ Training may improve water safety skills, ${ }^{18}$ but many drownings occur when children are not actually swimming but walking or playing near pools, thereby limiting any effect this measure may have. ${ }^{2} 131519$

The inadequacy of other countermeasures leaves pool fencing as the only practical intervention currently available to prevent preschoolers from drowning in domestic swimming pools. There is evidence, however, that few people fence their pools voluntarily. ${ }^{20}{ }^{21}$ Moreover, many owners actively dispute the need for fencing. ${ }^{22}{ }^{23}$ There is a need, therefore, for legislation making fencing mandatory. ${ }^{8}$

New Zealand introduced mandatory fencing with the passing of the Fencing of Swimming Pools Act 1987 (FOSP Act). ${ }^{24}$ This act requires domestic swimming pools, including spa pools, to be fenced (see table 1). Since the introduction of the act, the average number of preschoolers drowning in domestic pools each year has halved from eight to four (Water Safety New Zealand, unpublished data). Under this legislation, authorities (local government) have responsibility for ensuring compliance. Since 1991 the act has been supplemented by the Building Act 1991 that requires that a building consent be obtained for all new pools before construction. $^{25}$ For consent to be granted, 
Table 1 Summary of the Fencing of Swimming Pools Act 1987*

Who does the act apply to?

- Pool owners must advise their authority that they have a pool.

- Authorities must take all reasonable steps to make sure the act is complied with.

What pools need to be fenced?

- All private swimming pools and spa pools, unless the maximum depth is $400 \mathrm{~mm}$ or less, or the walls are $1.2 \mathrm{~m}$ or higher, or the pool is indoors.

Where must the fence be situated?

- The fence must only surround the pool and the area immediately around the pool.

- A boundary fence alone is not sufficient. Buildings can form part of the fence.

Can pool owners be exempted from the act?

- Authorities can grant exemptions, if they are satisfied the pool does not significantly increase danger to young children.

What standard of fencing is required?

- The fence must be $1.2 \mathrm{~m}$ high.

- Any horizontal supports on the outside of the fence must be at least $900 \mathrm{~mm}$ apart.

- Where fences are made of mesh, holes must be less than $50 \mathrm{~mm}$ wide (if holes are between 10 $\mathrm{mm}$ and $500 \mathrm{~mm}$ wide, the fence must be $1.8 \mathrm{~m}$ high).

- Gates and doors must be self closing, with a latch.

- Latches must be at least $1.2 \mathrm{~m}$ above the ground if on the pool side of the fence, or $1.5 \mathrm{~m}$ if on the outside.

- Where a building forms a part of a fence, the requirements for doors may not apply.

* Adapted from Department of Internal Affairs. Guidelines for Territorial Authorities on the Fencing of Swimming Pools Act 1987. Wellington: Department of Internal Affairs, 1990. ${ }^{29}$

plans must demonstrate compliance with the Building Code (and compliance with the FOSP Act is one method of demonstrating this). ${ }^{26}$

In 1991, a study of the progress authorities were making in enforcement of the FOSP Act was conducted. ${ }^{27}$ One of the key points to emerge from this was that while $93 \%$ of authorities had procedures in place for the inspection of new pools, and $67 \%$ for existing pools (predating the act), only $25 \%$ undertook regular inspections to ensure continuing compliance. This study also revealed that $76 \%$ of authorities had difficulty in enforcing the act. Of these, $66 \%$ cited consumer resistance and $29 \%$ difficulties with the cost of enforcement. ${ }^{27}$ Recent research in Victoria, Australia, identified cost of enforcement, identification of pools, lack of owner knowledge, pool owner attitude, and cost of fencing as the main barriers to enforcement of pool fencing legislation in that state. ${ }^{28}$

The purpose of the current study was to build on the earlier research, by identifying the status of compliance with and enforcement of the FOSP Act 10 years after its introduction. A secondary purpose was to identify methods for improving compliance and the process of enforcement.

\section{Methods}

Two surveys were undertaken. The first involved a postal questionnaire, which was sent to the 74 authorities in New Zealand. Telephone follow ups were made to authorities who were slow to respond. Responses were received from 64 of the 74 authorities (87\%) in the timeframe allowed. The questionnaire included items on the number and compliance of pools, means of identifying pools and enforcing compliance, barriers to compliance and possible solutions, publicity undertaken, and administration of the act.

After the return of the postal questionnaires, a sample of 12 authorities was selected for telephone interviews. Selection was made on the basis of answers to the postal questionnaire.
Table 2 Compliance status of pools ( $n=54$ territorial authorities)

\begin{tabular}{lc}
\hline & No (\%) of pools \\
\hline Compliant & $22448(47.4)$ \\
Not compliant & $9125(19.3)$ \\
$\begin{array}{l}\text { Compliance status not known or not } \\
\text { specified }\end{array}$ & $15810(33.3)$ \\
Total & $47383(100)$ \\
\hline
\end{tabular}

Authorities more actively enforcing the FOSP Act were contacted, so as to identify examples of "best practice". A semistructured questionnaire was used, covering the same general topics as the first survey while seeking elaboration and examples.

\section{ANALYSIS}

Summary statistics are supplemented with qualitative comments obtained from the postal questionnaire and telephone interviews. Relationships between responses were examined using binomial regression analyses. Where percentages are reported these are based on responses from the 64 authorities who completed the questionnaire, unless an alternative total is indicated.

The total number of pools in New Zealand was estimated by summing the numbers reported by the authorities. For those not providing this information, the number of pools was estimated by taking the geometric mean of those neighbouring authorities for which figures were available. These estimates were added to the total reported by authorities.

\section{Results}

IDENTIFICATION OF POOLS AND THEIR

COMPLIANCE STATUS

Of the 74 authorities in New Zealand, 53 provided information on the number of domestic swimming pools in their area. A total of 47383 pools were identified. The total number of pools was then estimated at 59485 , using the method described above, giving rates of 46 pools/1000 dwellings and 16 pools/1000 persons.

Table 2 presents the compliance status of pools, based on those authorities who reported the number of pools in their area. Some authorities provided actual figures, while others provided estimates. Some were unable to provide complete information on compliance status. Pools of uncertain status are included in the category "status not known or not specified" in table 2. Some included above ground pools while other did not (see table 3 ).

Authorities have the power to grant exemptions from the requirements of the act, if a lack of fencing "would not significantly increase danger to young children" (section 6, subsection 1). Thirty per cent of authorities had granted exemptions in the 12 months before the survey, including $11 \%$ for spa pools with covers meeting certain requirements (see table 3).

Few authorities (9\%) had written policies or procedures for locating and inspecting pools 
Table 3 Inconsistencies in interpretation and enforcement

\begin{tabular}{ll}
\hline Issue & Inconsistencies/difficulties \\
\hline Above ground pools & Authorities varied over whether building consent was \\
required for above ground pools under the Building \\
Code. $52 \%$ believed it was, $14 \%$ believed it was not, and \\
$38 \%$ believed it varied according to features such as the \\
height of the pool sides, capacity of the pool, or the \\
depth of water. \\
If spa pool covers were solid, lockable, and able to sustain \\
the weight of a child, some authorities granted \\
exemptions (11\%). Others indicated that spa pool covers \\
would not be granted exemptions in any circumstance. \\
The fenced area must not be more than the area used "in \\
conjunction with the use of the pool". Authorities noted \\
difficulties in defining what that area can contain, and \\
what size it can be. Although guidelines have been \\
produced, these do not carry the weight of law and can \\
be contested. \\
Only some authorities (38\%) required self closing \\
mechanisms on sliding/folding doors that allow access \\
from the house to the pool area. This inconsistency \\
appeared to arise from differences between the \\
requirements of the Fencing of Swimming Pools Act and \\
the requirements of the Building Code. \\
Where a pool fence relies partly on a perimeter fence \\
compliance is sometimes affected by the actions of \\
neighbours, making enforcement difficult. Examples \\
include neighbours altering the fence or placing objects \\
near to it, making it scalable by children.
\end{tabular}

not identified through the building consent procedures. There was no statistically significant relationship between having such a policy and the reported rate of compliance with the FOSP Act $\left(\chi_{1}^{2}=0.58, \mathrm{p}=0.45\right)$. It was more common for authorities to have a programme of reinspection to ensure that pools continued to comply $(28 \%)$. Again, there was no statistically significant relationship between having such a programme and reported compliance levels $\left(\chi_{1}^{2}=0.71, \mathrm{p}=0.40\right)$.

When asked to identify problems with enforcing the FOSP Act, $86 \%$ of authorities identified one or more problems, including pool owner resistance $(84 \%)$, locating existing pools $(76 \%)$, cost of administration (63\%), and interpretation of the act $(64 \%)$. Issues relating to interpretation of the act included defining the "immediate pool area" and the acceptability of access via house doors, both noted by $41 \%$ (see table 3). Another issue raised was the cost of enforcement, with $11 \%$ of authorities saying they would be more vigilant in enforcement if costs could be more easily recovered.

Inconsistencies and difficulties in interpretation of the act are summarised in table 3.

IMPROVING COMPLIANCE AND ENFORCEMENT

Two thirds of authorities suggested solutions for overcoming common barriers to compliance. The more commonly mentioned solutions were publicity or education (44\%), amendments to clarify the act (13\%), additional resources to cover the cost of enforcement $(11 \%)$, and greater use of litigation, including the introduction of instant fines $(8 \%)$.

During the telephone survey respondents were asked to describe any educational campaigns or other initiatives they had taken to encourage compliance. Examples given included educating real estate agents and lawyers on the requirements of the act for the purpose of advising their clients, and free advisory visits to any households with, or considering building, pools.

During the 12 months before the survey, $52 \%$ of authorities had notified the public at large of their obligations under the act, with newspaper articles being the most common method used (37\%). There was no statistically significant relationship between public notification and reported compliance levels $\left(\chi_{1}^{2}=0.05, \mathrm{p}=0.82\right)$. In the telephone survey, however, authorities expressed the view that publicity campaigns led to the identification of pools not already on their records, through inquiries from owners and from anonymous "tip offs".

\section{Discussion}

New Zealand's pool fencing FOSP Act provides a means to prevent children from drowning, but its effectiveness is being compromised by a low level of compliance. This study identified two major factors limiting the act's effectiveness: (1) inconsistencies between authorities in their enforcement of particular requirements, largely due to ambiguities in the legislation, and (2) some authorities making little attempt to locate pools or monitor compliance.

\section{INCONSISTENCIES IN ENFORCEMENT}

Three areas of inconsistent enforcement were identified: (1) the acceptability of spa pool covers, (2) the definition of the immediate pool area, and (3) the acceptability of sliding doors without self closing mechanisms. Inconsistent enforcement in relation to spa pool covers has created confusion for manufacturers, retailers, and purchasers in regions where neighbouring authorities have differing policies. This problem is particularly evident in Auckland, New Zealand's largest city, where four authorities exist within the metropolitan area. On the confusion over definition of the immediate pool area, guidelines have been produced to aid interpretation, ${ }^{29}$ but these do not carry the weight of law and could be successfully challenged. Introducing a more prescriptive definition, however, would reduce the opportunity for common sense solutions and be contrary to the current trend in New Zealand for performance based legislation. The problem with sliding doors arises due to a variation in definition (although not necessarily intent) between the Building Code, and the schedule to the FOSP Act. Because of this, some authorities appear to be confused as to whether such doors should be allowed. It is unknown how many pools have been affected by these inconsistencies, but as a result of them the standard of fencing required varies across New Zealand.

IDENTIFICATION AND MONITORING OF POOLS This study found no statistically significant relationship between the reported rate of pools complying with the act, and three different 
means of identifying pools or monitoring compliance: (1) having a written policy or procedure for locating pools, (2) having a programme for reinspection, and (3) notifying the public of their obligations under the act. While this may appear surprising, it can probably be explained by the inconsistencies between authorities in the reporting of compliance. Authorities using one or more of the above means are more likely to have been aware of the current status of pools in their area. In contrast, figures based on the status of pools when installed, or when the act came into force, would not necessarily reflect the current compliance status. Accordingly, it is likely that authorities not using the above means overestimated the level of compliance in their area. Other possibilities, however, are that the more aggressive authorities are overstating their level of enforcement, or alternatively, that more aggressive enforcement does not translate into increased compliance.

It is also apparent from this study that pools are being installed without authorities being notified. This may be particularly true of above ground pools that are easily purchased and assembled. If a higher level of compliance is to be achieved, greater effort needs to be made to identify these pools, and to ensure that their owners are aware of the requirement to notify authorities of the pool. A similar problem was identified in Victoria, Australia, where only $37 \%$ of municipalities were able to provide an estimate of the number of pools, as pools costing less than $\mathrm{A} \$ 5000$ did not require a permit for construction. ${ }^{28}$ One method for ensuring owners are aware of the requirements for pool fencing would be to place responsibility on pool retailers to bring the requirements to the attention of purchasers or, alternatively, to require that retailers notify authorities of all pool purchases.

Knowledge of the compliance status of pools is complicated by reportedly inadequate definitions in the act (for example, of the immediate pool area; see table 3). As authority staff and/or elected representatives change, the interpretation of what is acceptable under the act is open to change. As a consequence, some authorities were only able to estimate current compliance, as the compliance status of pools may have changed with changing interpretations of the act. Greater consistency in the interpretation of the requirements is needed to reduce this uncertainty for both pool owners and authorities.

There was a call from authorities for a national education and/or publicity campaign to be conducted to support their enforcement activities. Previous research has shown that awareness of the danger of an unfenced pool, or a belief that pools should be fenced, is not sufficient to make people fence their pool. ${ }^{20} 2130$ Such a campaign should, therefore, also publicise the requirements of the act, and the possibility of legal action against those who do not comply. Ideally it should be centrally funded, thus taking some of the financial burden for enforcement from authorities, who are presently the only financial contributors to enforce- ment of the act. The cost of enforcement was identified as a barrier by some regulatory authorities in both this and a previous New Zealand study ${ }^{27}$ as well as in Victoria, Australia. ${ }^{28}$

\section{Implications for prevention}

This study has shown that, where there is ambiguity in legislation intended to promote safety from injury, enforcement is inconsistent and compliance incomplete. As a result, in New Zealand, children will continue to drown unnecessarily until the ambiguities are removed and there is an improvement in the culture of enforcement and compliance. As for other injury prevention measures, ${ }^{28} 31$ this study has demonstrated that legislation by itself is not sufficient to ensure the safety of children. Legislation needs to be enforced to be effective, and research into the barriers that prevent legislation from being effectively enforced is crucial.

The Injury Prevention Research Unit is funded jointly by the Accident Rehabilitation and Compensation Insurance Corporation, and the Health Research Council of New Zealand. The research described was commissioned by Water Safety New Zealand. The authors would like to thank members of Water Safety New Zealand's Consultative Group on Pool Fencing for their helpful comments on this research.

1 Langley JD, Smeijers J. Injury mortality among children and teenagers in New Zealand compared with United States of America. Inj Prev 1997;3:195-9.

2 Pitt WR, Balanda KP. Childhood drowning and neardrowning in Brisbane: the contribution of domestic pools. Med F A ust 1991;154:661-5.

3 Cass DT, Ross F, Lam LT. Childhood drowning in New South Wales 1990-1995: a population-based study. Med F Aust 1996;165:610-12.

4 Warneke CL, Cooper SP. Child and adolescent drownings in Harris County, Texas, 1983 through 1990. Am f Public Health 1994;84:593-8.

5 Ellis AA, Trent RB. Swimming pool drownings and near-drownings among California preschoolers. Public Health Rep 1997;112:73-7.

6 Kemp A, Sibert JR. Drowning and near drowning in children in the United Kingdom: lessons for prevention. BMF 1992;304:1143-6.

7 Riley MD, Larson A, Langford J. Drowning fatalities of children in Tasmania: differences from national data. Aust N Z F Public Health 1996;20:547-9.

8 Langley J. Fencing of private swimming pools in New Zealand. Community Health Studies 1983;7:285-9.

9 Pearn JH, Wong RYK, Brown J, et al. Drowning and near-drowning involving children: a five-year total population study from the city and county of Honolulu. $A m \mathcal{F}$ Public Health 1979;69:450-4

10 Milliner N, Pearn J, Guard R. Will fenced pools save lives? A 10-year study from Mulgrave Shire, Queensland. Med f Aust 1980;ii:510-11.

11 Nixon J, Pearn J, Wilkey I, et al. Fifteen years of child drowning: a 1967-1982 analysis of all fatal cases from the Brisbane Drowning Study and an 11 year study of consecutive near-drowning cases. Accid Anal Prev 1986;18: 199-203.

12 Fergusson DM, Horwood LJ. Risks of drowning in fenced and unfenced domestic swimming pools. NZ Med F 1984; 97:777-9.

13 Wintemute GJ. Childhood drowning and near-drowning in the United States. Am F Dis Child 1990;144:663-9.

14 Fergusson DM, Horwood LJ, Shannon FT. Domestic swimming pool accidents to pre-school children. NZ Med f 1983;96:725-7.

5 Gardiner SD, Smeeton WMI, Koelmeyer TD, et al. Accidental drownings in Auckland children. $N Z$ Med $\mathscr{f}$ 1985;98:579-82.

16 Cass DT, Ross FI, Grattan-Smith TM. Child drownings: a changing pattern. Med f Aust 1991;154:163-5.

17 Fisher KJ, Balanda KP. Caregiver factors and pool fencing: an exploratory analysis. Inj Prev 1997;3:257-61.

18 Asher KN, Rivara F, Felix D, et al. Water safety training as a potential means of reducing risk of children's drowning. Inj potential means of reduc
Prev 1995;1:228-33.

19 Barss P. Cautionary notes on teaching water safety skills. Inj Prev 1995;1:218-19.

20 Fergusson DM, Horwood LJ, Shannon FT. The safety standards of domestic swimming pools $1980-1982$. N Z Med f 1983;96:93-5. 
21 Wintemute GJ, Wright MA. The attitude-practice gap revisited: risk reduction beliefs and behaviors among owners of residential swimming pools. Pediatrics 1991;88:116871.

22 Wintemute GJ, Wright MA. Swimming pool owners' opinions of strategies for prevention of drowning. Pediatrics 1990;85:63-9.

23 Carey V, Chapman S, Gaffney D. Children's lives or garden aesthetics? A case study in public health advocacy. Aust $\mathcal{F}$ Public Health 1994;18:25-32.

24 New Zealand Government. Fencing of swimming pools act. Wellington: New Zealand Government, 1987.

25 New Zealand Government. Building act. Wellington: New Zealand Government, 1991 .

26 New Zealand Government. Building regulations. Wellington: New Zealand Government, 1992.
27 Child Accident Prevention Foundation of New Zealand. Survey of local authorities on the fencing of swimming pools act 1987. Wellington: National Childhood Injury Prevention Forum, 1991.

28 Ashby K, Routley V, Stathakis V. Enforcing legislative and regulatory injury prevention strategies. Hazard: Victorian Injury Surveillance System 1998;34(March):1-12.

29 Department of Internal Affairs Guidelines for territorial authorities on the fencing of swimming pools act 1987. Wellington: Department of Internal Affairs, 1990.

30 Pearn J, Nixon J. Prevention of childhood drowning accidents. Med f Aust 1977;i:616-18.

31 Plumridge E, McCool J, Chetwynd J, et al. Purchasing a cycle helmet: are retailers providing adequate advice? Inj Prev 1996;2:41-3.

\section{Random thoughts from 30 years ago}

The following are some quotations from a genuine "classic", the Child and his Symptoms: A Comprehensive Approach, by John Apley and Ronald Mackeith (2nd edition, Blackwell Scientific Publications, Oxford and Edinburgh, 1968; ISBN 632-001-180).

\section{On traffic accidents:}

What is known about these collisions? (It is suggested, and we agree, that collision is a better word than accident, for a collision is expected to have a cause, while an accident is more likely to be dismissed as "accidental") (p 79). Editor's comment: Plus ça change? We agree, of course.

More on traffic accidents:

The more immediate methods for diminishing traffic accidents have been described as the three E's:

- Engineering - cars and roads must be efficient, but, though improving the roads yields economic dividends by speeding transport, it results in little diminution of accidents.

- Enforcement of the laws helps a little.

- Education helps most.

Editor's note: We disagree, of course. These opinions are not "evidence based"; it is enforcement that helps most and education that helps only a little. Still, the three E's are right and seemingly well ahead of their time (BP).

\section{Injured child workers}

An astounding statistic reported in a UK weekly suggests that more than 500000 child workers are injured in the course of their employment each year. The report, from the Low Pay Unit, adds that "unless young workers are monitored more closely the toll could soon be worse". Although I was astonished by the figure, I was equally amazed to learn that "little work has been done on the hazards of modern child labour in the UK" and that "the current rules governing child labour date back to the $1840 \mathrm{~s}$ " when they addressed problems such as those of chimney sweeps! In two areas studied the rate of workplace injuries in the past year ranged from $37 \%$ to $44 \%$ and it is acknowledged that apart from fatalities, injury rates are probably under-reported because employers "hush-up many cases". It is up to local authorities to decide the extent to which they enforce such rules as do exist. Only one company was taken to court in 1997-98 and was fined $£ 500$. Regrettably, the government has opted out of a European Union directive strengthening child labour laws (from the Observer, 28 February 1999) (BP).

\section{.......and finally}

Carriages without horses shall go, And accidents shall fill the world with woe Mother Simpson's Prophecies (15th C) 